Е. И. Грушова, В. И. Жолнеркевич

Белорусский государственный технологический университет

\title{
СРАВНИТЕЛЬНЫЙ АНАЛИЗ ЭКСТРАГИРУЮЩЕЙ СПОСОБНОСТИ РАСТВОРИТЕЛЕЙ ДЛЯ ОЧИСТКИ АРОМАТИЧЕСКИХ МАСЕЛ ОТ ПОЛИЦИКЛИЧЕСКИХ АРОМАТИЧЕСКИХ УГЛЕВОДОРОДОВ
}

Приведены сравнительные экспериментальные данные экстракционной очистки образцов ароматического масла, полученных в процессе селективной очистки нефтяных вакуумных дистиллятов различной вязкости ВД-2 и ВД-3 фенолом, от полициклических ароматических углеводородов диметилсульфоксидом и смесью 90 мас. \% N-метилпирролидона с 10 мас. \% этиленгликоля. Экстракционную очистку осуществляли в одну ступень при температуре $50^{\circ} \mathrm{C}$ и кратности растворителя к сырью, равной 2:1 мас. ч. Проведен анализ полученных продуктов каждого эксперимента, составлены материальные балансы. Методом ИК-спектроскопии исследован структурно-групповой состав образцов ароматического масла до и после экстракционной очистки. На основании ИК-спектров оценивали условное содержание и соотношение ароматических и парафиновых структур в ароматических маслах. Установлено, что более высокая растворяющая способность смеси N-метилпирролидона с этиленгликолем позволяет интенсифицировать извлечение ароматических полициклических структур в экстракт второй ступени. Показано, что эффективность селективной очистки зависит как от состава и свойств исходного сырья, так и от свойств экстрагента, а применение ИК-спектроскопии позволяет быстро и качественно охарактеризовать эффективность процесса селективной очистки образцов ароматического масла от полициклических ароматических структур.

Ключевые слова: ароматическое масло, жидкостная экстракция, диметилсульфоксид, смесь $\mathrm{N}$-метилпирролидона с этиленгликолем, ИК-спектроскопия.

Для цитирования: Грушова Е. И., Жолнеркевич В. И. Сравнительный анализ экстрагирующей способности растворителей для очистки ароматических масел от полициклических ароматических углеводородов // Труды БГТУ. Сер. 2, Химические технологии, биотехнологии, геоэкология. 2021. № 2 (247). С. 133-137.

\section{E. I. Grushova, V. I. Zholnerkevich \\ Belarusian State Technological University \\ COMPARATIVE ANALYSIS OF EXTRACTIVE CAPACITY SOLVENTS FOR CLEANING AROMATIC OILS FROM POLYCYCLIC AROMATIC HYDROCARBONS}

Comparative experimental data on the extraction purification of aromatic oil samples obtained in the process of selective purification of petroleum vacuum distillates of different viscosities VD-2 and VD-3 with phenol from polycyclic aromatic hydrocarbons with dimethylsulfoxide and a mixture of $90 \mathrm{wt} . \%$ $\mathrm{N}$-methylpyrrolidone with $10 \mathrm{wt}$ \% ethylene glycol. Extraction purification was carried out in one step at a temperature of $50^{\circ} \mathrm{C}$ and the multiplicity of the solvent to the raw material equal to $2: 1 \mathrm{wt}$. h. The analysis of the obtained products of each experiment was carried out, material balances were compiled. The structural and group composition of aromatic oil samples before and after extraction purification was studied by IR spectroscopy. On the basis of IR spectra, the conditional content and the ratio of aromatic and paraffin structures in aromatic oils were evaluated. It is shown that the efficiency of selective purification depends both on the composition and properties of the feedstock and on the properties of the extractant, and the use of IR spectroscopy allows us to quickly qualitatively characterize the efficiency of the process of selective purification of aromatic oil samples from polycyclic aromatic structures.

Kew words: aromatic oil, liquid extraction, dimethyl sulfoxide, mixture of N-methylpyrrolidone with ethylene glycol, IR spectroscopy.

For citation: Grushova E. I., Zholnerkevich V. I. Comparative analysis of extractive capacity solvents for cleaning aromatic oils from polycyclic aromatic hydrocarbons. Proceedings of BSTU, issue 2, Chemical Engineering, Biotechnologies, Geoecology, 2021, no. 2 (247), pp. 133-137 (In Russian).

Введение. Среди группы химических соединений, способных к бионакоплению и обладающих канцерогенными, мутагенными и токсическими свойствами, особое место занимают 4-5-кольчатые полициклические ароматические углеводороды (ПАУ), поскольку образуются они 
в процессах сжигания и переработки нефтепродуктов, угля, древесины, мусора и т. д. [1]. В достаточно больших масштабах ПАУ используются при производстве шин и резинотехнических изделий, так как входят в состав нефтяных масел-пластификаторов, мировое потребление которых оценивается на уровне 1,5 млн/т год $[2,3]$. Поэтому разработке эффективных методов обработки нефтехимического сырья для удаления полициклических ароматических углеводородов в настоящее время уделяется большое внимание [3-5].

Наибольшее распространение получили технологии экстракционной очистки нефтяных фракций от ПАУ, подчиняющиеся закономерностям жидкостной экстракции масляного сырья с применением селективных растворителей, в число которых входят диметилсульфоксид и Nметилпирролидон, содержащий 10 мас. \% этиленгликоля [4, 6]. Согласно [6], для улучшения контакта фаз при очистке от ПАУ вязкого ароматического масла перед началом процесса исходное сырье смешивают с промежуточным низкокипящим углеводородным растворителем, что приводит к увеличению затрат на технологический процесс.

Поэтому весьма актуальной задачей является разработка экстрагента, обеспечивающего эффективное выделение ПАУ из ароматического масла без применения дополнительного низкокипящего углеводородного растворителя.

В данной работе представлены результаты первого этапа исследований, а именно данные для сравнительного анализа экстрагирующей способности диметилсульфоксида (ДМСО) и растворителя состава $\mathrm{N}$-метилпирролидон $(\mathrm{N}-\mathrm{MП})+$ +10 мас. \% этиленгликоля (ЭГ) при очистке экстрактов (ароматических масел), выделенных из нефтяных вакуумных дистиллятов ВД-2 и ВД-3 в промышленных условиях с применением фенола в ОАО «Нафтан». Характеристика экстрактов представлена в табл. 1 .

Основная часть. Экстракционную обработку экстрактов, полученных в процессе селективной очистки вакуумных дистиллятов ВД-2 и ВД-3, проводили ДМСО и составом N-MП + 10 мас. \% ЭГ при температуре $50^{\circ} \mathrm{C}$ и кратности растворитель:сырье, равной 2:1 мас. ч. Процесс осуществляли в термостатированной делительной воронке, оснащенной мешалкой. В воронкуэкстрактор загружали сырье (экстракты ВД-2 и ВД-3), растворитель и перемешивали 30 мин. Отстой системы проводили не менее 20 мин. Далее полученные фазы (рафинатные и экстрактные растворы) разделяли. Экстракт из экстрактного раствора выделяли вакуумной отгонкой растворителя. Рафинатный раствор промывали водой до показателя преломления промывных вод $n_{D}{ }^{20}=1,3333$. Рафинат сушили над цеолитом $\mathrm{NaA}$ и анализировали.

Анализ структурно-группового состава исходного сырья, полученных продуктов-экстрактов осуществляли методом ИК-спектроскопии. ИК-спектры анализируемых образцов ароматических масел регистрировали с помощью ИКФурье спектрометра (ФСМ 1202 ООО «Инфраспек») в интервале волновых чисел 4000-400 $\mathrm{cm}^{-1}$. Испытуемый образец наносили в виде тонкого слоя на кристалл $\mathrm{KBr}$. Отношение полос поглощения в ИК-спектрах проводилось в соответствии с литературными данными [7-9]. На ИКспектрах рафинатов (очищенное ароматическое масло) и экстрактов второй ступени фиксировали широкий набор полос поглощения, относимых к ароматическим структурам разного строения - 1600-1603 $\mathrm{cm}^{-1}, 865-867 \mathrm{~cm}^{-1}, 811-812 \mathrm{~cm}^{-1}$, 746-747 $\mathrm{cm}^{-1}, 1168-1170 \mathrm{~cm}^{-1}$ и к алкановым структурам - 720-726 см ${ }^{-1}, 1458-1463 \mathrm{~cm}^{-1}$.

В данной работе на основании ИК-спектров оценивали условное содержание и соотношение ароматических и парафиновых структур в ароматическом масле $[10,11]$ :

$\mathrm{C}_{1}=D_{1600} /\left(D_{720}+D_{1380}\right)-$ условное отношение ароматических структур к парафиновым структурам;

$\mathrm{C}_{2}=D_{1600} / D_{1460}-$ условное содержание ароматических структур;

$\mathrm{C}_{3}=\left(D_{748}+D_{810}+D_{860}+D_{1170}\right) / D_{1600}-$ условное отношение полиалкилзамещенных моно-, би- и трициклических ароматических структур к ароматическим структурам;

$\mathrm{C}_{4}=\left(D_{748}+D_{810}+D_{860}+D_{1170}\right) / D_{1460}-$ условное содержание полиалкилзамещенных моно-, би- и трициклических ароматических структур;

$\mathrm{C}_{5}=\left(D_{810}+D_{860}+D_{1170}\right) / D_{1460}-$ условное содержание полизамещенных конденсированных ароматических структур;

$D$ - оптическая плотность полос поглощения на соответствующей частоте.

Основные показатели экстракционной очистки ароматических масел приведены в табл. 1, а структурно-группового анализа ароматических масел первой и второй ступеней очистки в табл. 2.

Сопоставление результатов очистки экстрактов, выделенных из вакуумных дистиллятов ВД-2 и ВД-3 фенолом, позволило установить следующее. С увеличением вязкости исходного сырья выход очищенного ароматического масла (рафината) возрастает (табл. 1). Однако этот эффект в большей степени проявляется при очистке ароматического масла растворителем N-MП + 10 мас. \% ЭГ. Селективность очистки возрастает с увеличением вязкости сырья, а при переходе от растворителя ДМСО к растворителю N-MП + 10 мас. \% ЭГ уменьшается почти в 12 раз при переработке менее вязкого сырья и в 5,5 раза - более вязкого сырья. 
Основные показатели экстракционной очистки ароматических масел, выделенных из вакуумных дистиллятов ВД-2 и ВД-3

\begin{tabular}{|c|c|c|c|c|c|}
\hline \multirow[b]{2}{*}{$\begin{array}{c}\text { Объект } \\
\text { исследования }\end{array}$} & \multirow[b]{2}{*}{ Показатель } & \multicolumn{2}{|c|}{ Экстракт ВД-2 } & \multicolumn{2}{|c|}{ Экстракт ВД-3 } \\
\hline & & ДМСО & $\begin{array}{c}\text { N-MП + } \\
+10 \text { мас. \% } \\
\text { ЭГ }\end{array}$ & ДМСО & $\begin{array}{c}\text { N-MП + } \\
+10 \text { мас. \% } \\
\text { ЭГ }\end{array}$ \\
\hline \multirow[t]{3}{*}{ Сырье (экстракт) } & Показатель преломления $n_{D}{ }^{50}$ & \multicolumn{2}{|c|}{1,5380} & \multicolumn{2}{|r|}{1,5410} \\
\hline & Анилиновая точка, ${ }^{\circ} \mathrm{C}$ & \multicolumn{2}{|c|}{46,5} & \multicolumn{2}{|r|}{44,5} \\
\hline & $\begin{array}{l}\text { Вязкостно-температурная характери- } \\
\text { стика } v_{50} / v_{70}\end{array}$ & \multicolumn{2}{|c|}{3,02} & \multicolumn{2}{|r|}{3,39} \\
\hline \multirow{4}{*}{$\begin{array}{l}\text { Рафинат (очи- } \\
\text { щенное арома- } \\
\text { тическое масло) }\end{array}$} & Выход рафината, мас. \% & 92,88 & 25,23 & 93,03 & 50,36 \\
\hline & Показатель преломления рафината $n_{D}^{50}$ & 1,5300 & 1,5135 & 1,5410 & 1,5175 \\
\hline & Анилиновая точка рафината, ${ }^{\circ} \mathrm{C}$ & 57,5 & - & 55,5 & - \\
\hline & $\begin{array}{l}\text { Вязкостно-температурная } \\
\text { стика рафината } v_{50} / v_{70}\end{array}$ & 1,52 & - & 3,28 & - \\
\hline \multirow{3}{*}{$\begin{array}{l}\text { Экстракт второй } \\
\text { ступени очистки }\end{array}$} & Выход экстракта, мас. \% & 7,12 & 74,77 & 6,97 & 49,64 \\
\hline & Показатель преломления экстракта $n_{D}{ }^{50}$ & 1,6424 & 1,5463 & 1,6718 & 1,5655 \\
\hline & Селективность $\mathrm{S}=n_{D}{ }^{50}{ }_{\text {(экстр) }}-n_{D}{ }^{50}$ (сырья) & 0,1044 & 0,0083 & 0,1308 & 0,0235 \\
\hline
\end{tabular}

Спектральный коэффициент $\mathrm{C}_{1}$, характеризующий условное отношение ароматических структур к парафиновым структурам для экстракта ВД-2 больше, чем в экстракте ВД-3. При этом отношение полизамещенных моно-, би- и трициклических ароматических структур к ароматическим структурам $\left(\mathrm{C}_{3}\right)$ практически совпадают. Условное содержание ароматических структур $\left(\mathrm{C}_{2}\right)$ и полизамещенных ароматических структур $\left(\mathrm{C}_{4}, \mathrm{C}_{5}\right)$ в экстракте ВД-2 второй ступени очистки диметилсульфоксидом превышает аналогичный показатель, полученный при использовании для очистки растворителем N-MП - ЭГ. Однако при очистке экстракта ВД-3 наблюдается обратная зависимость, согласно которой более высокую растворяющую способность по отношению к ароматическим углеводородам проявляет растворитель N-MП - ЭГ. Таким образом, выявленные зависимости свидетельствуют о том, что эффективность очистки ароматического масла зависит как от состава и свойств исходного сырья, так и от природы растворителя.

В данном случае растворитель N-MП - ЭГ лучше использовать при селективной очистке более вязкого сырья. По-видимому, из-за высокой растворяющей способности системы N-MП - ЭГ условное отношение ароматических структур к парафиновым структурам нормального и изостроения, т. е. показатель $\mathrm{C}_{1}<1$ при очистке экстракта из ВД-2. Однако с увеличением вязкости исходного экстракта в экстракт второй ступени очистки больше переходит ароматических структур и показатель $\mathrm{C}_{1}$ более чем в 3 раза превышает аналогичный показатель для сырья, т. е. экстракта из ВД-3. Кроме того, следует отметить, что на величину показателя $\mathrm{C}_{3}$, характеризующего условное отношение полизамещенных ароматических структур к общему содержанию ароматических структур, мало влияет природа селективного растворителя.

Таблица 2

Результаты исследования структурно-группового состава экстрактов, выделенных из вакуумных дистиллятов ВД-2 и ВД-3

\begin{tabular}{|c|c|c|c|c|c|c|}
\hline \multirow[b]{2}{*}{ Показатель } & \multirow{2}{*}{$\begin{array}{l}\text { Экстракт } \\
\text { из ВД-2 }\end{array}$} & \multicolumn{2}{|c|}{$\begin{array}{c}\text { Экстракт второй } \\
\text { ступени }\end{array}$} & \multirow{2}{*}{$\begin{array}{l}\text { Экстракт } \\
\text { из ВД-3 }\end{array}$} & \multicolumn{2}{|c|}{$\begin{array}{c}\text { Экстракт второй } \\
\text { ступени }\end{array}$} \\
\hline & & ДМСО & $\begin{array}{c}\text { N-MП + } \\
+10 \text { мас. \% } \\
\text { ЭГ }\end{array}$ & & ДМСО & $\begin{array}{c}\text { N-MП + } \\
+10 \text { мас. \% } \\
\text { ЭГ }\end{array}$ \\
\hline $\mathrm{C}_{1}=\mathrm{D}_{1600} /\left(\mathrm{D}_{720}+\mathrm{D}_{1380}\right)$ & 1,82 & 2,07 & 0,63 & 0,59 & 1,10 & 2,04 \\
\hline $\mathrm{C}_{2}=\mathrm{D}_{1600} / \mathrm{D}_{1460}$ & 3,22 & 6,08 & 2,39 & 2,31 & 4,33 & 5,44 \\
\hline $\mathrm{C}_{3}=\left(\mathrm{D}_{740}+\mathrm{D}_{810}+\mathrm{D}_{860}+\mathrm{D}_{1170}\right) / \mathrm{D}_{1600}$ & 4,32 & 3,87 & 3,72 & 4,00 & 3,63 & 4,07 \\
\hline $\mathrm{C}_{4}=\left(\mathrm{D}_{740}+\mathrm{D}_{810}+\mathrm{D}_{860}+\mathrm{D}_{1170}\right) / \mathrm{D}_{1460}$ & 13,92 & 23,54 & 8,87 & 9,27 & 15,72 & 22,33 \\
\hline$C_{5}=\left(D_{810}+D_{860}+D_{1170}\right) / D_{1460}$ & 11,17 & 19,06 & 6,89 & 7,18 & 12,48 & 17,58 \\
\hline
\end{tabular}


Заключение. Результаты проведенных исследований показали, что при переработке экстрактов ВД-2 и ВД-3 замена диметилсульфоксида на смесь $\mathrm{N}$-метилпирролидона с этиленгликолем на второй ступени селективной очистки позволяет получить очищенное ароматическое масло с меньшим содержанием ароматических полициклических структур, если очистке подвергают более вязкое сырье - экстракт ВД-3. Без данных структурногруппового состава ароматического масла до и после селективной очистки определить оптимальные условия экстракционной очистки ароматического масла от канцерогенных полициклических углеводородов практически невозможно.

\section{Список литературы}

1. Проблемы загрязнения продукции резиновой промышленности полициклическими ароматическими углеводородами / Н. А. Охотина [и др.] // Вестн. Казан. технол. ун-та. 2013. Т. 16, № 3. C. $129-131$.

2. Технологии производства экологически безопасных масел-пластификаторов / С. В. Заглядова [и др.] // Нефтехимия. 2017. Т. 57, № 6. С. 726-736.

3. Кожевников Д. А. Разработка технологии производства масел-пластификаторов шинных резин: дис. ... канд. техн. наук: 05.17.07 / РГУ нефти и газа имени И. М. Губкина. М., 2014. 119 л.

4. Технологии получения экологически безопасных масел-пластификаторов различных типов / С. А. Антонов [и др.] // Химия и технология топлив и масел. 2020. № 3. С. 35-45.

5. Способ очистки ароматических экстрактов, содержащих ароматические полициклические соединения: пат. 2547695 Рос. Федерация, № 2012142734/04; заявл. 07.04.2011; опубл. 10.04.2015. Бюл. № $14.14 \mathrm{c}$.

6. Экстракционная очистка ароматических масел-мягчителей от канцерогенных полициклических аренов диметилсульфоксидом и смешанным экстрагентом N-метилпирролидон-этиленгликоль / А. А. Гайле [и др.] // Журнал прикладной химии. 2020. Т. 93, вып. 7. С. 1012-1017.

7. Глебовская Е. А. Применение инфракрасной спектроскопии в нефтяной геохимии. Л.: Недра, 1971. $140 \mathrm{c}$.

8. Origin based classification of crude oils by infrared spectrometry and chemometrics / A. B. Garmarudi [et al.] // Fuel. 2019. Vol. 236. P. 1093-1099.

9. Guiliano M., Millef Kister J., Muller J. F. Etude des specters IRTF de charbons francais demineralises et de leurs maceraux // Chim. Physique. 1988. Vol. 85. P. 963-970.

10. Артемьев В. Ю., Григорьев Е. В., Шигидин О. А. Инфракрасная спектрометрия как один из методов контроля при разработке ачимовских отложений Уренгойского НГКМ // Вестн. газ. науки. 2013. № 1 (12). С. 21-26.

11. Иванова Л. В., Сафиева Р. З., Кошелев В. Н. ИК-спектрометрия в анализе нефти и нефтепродуктов // Вестн. Башк. ун. 2008. Т. 13, № 4. С. 869-874.

\section{References}

1. Okhotina N. A., Sharipov E. N., Il'yazov M. F., Efimov M. V. Problems of contamination of rubber industry products with polycyclic aromatic hydrocarbons. Vestnik Kazanskogo tekhnologicheskogo universiteta [Bulletin of the Kazan Technological University], 2013, vol. 16, no. 3, pp. 129-131 (In Russian).

2. Zaglyadova S. V., Antonov S. A., Maslov I. A., Kitova M. V., Rudyak K. B., Leymeter T. D. Technologies for the production of environmentally friendly plasticizer oils. Neftekhimiya [Petrochemical], 2017, vol. 57, no. 6, pp. 726-736 (In Russian).

3. Kozhevnikov D. A. Razrabotka tekhnologii proizvodstva masel-plastifikatorov shinnykh rezini: Dis. kand. tekhn. nauk [Development of technology for the production of plasticizer oils for tire rubbers. Cand. Diss.]. Moscow, 2014. 119 p.

4. Antonov S. A., Tonkonogov B. P., Kilkova A. Yu., Dorogochinskaya V. A. Technologies for producing environmentally friendly plasticizer oils of various types. Khimiya i tekhnologiya topliv i masel [Chemistry and technology of fuels and oils], 2020, no. 3, pp. 35-45 (In Russian).

5. Ehdli L., Dzhelassi S., Pjul'vin S., Toma D. Sposob ochistki aromaticheskikh ekstraktov, soderzhashchikh aromaticheskiye politsiklicheskiye soyedineniya [Method of purification of aromatic extracts containing aromatic polycyclic compounds]. Patenr RF, no. 2547695, 2015.

6. Gayle A. A., Klement'yev V. N., Shchepalov A. A., Vorob'yeva A. R. Extraction purification of aromatic softener oils from carcinogenic polycyclic arenes with dimethylsulfoxide and a mixed extractant $\mathrm{N}$-methylpyrrolidone-ethylene glycol. Zhurnal prikladnoy khimii [Journal of Applied Chemistry], 2020, vol. 93, issue 7, pp. 1012-1017 (In Russian).

7. Glebovskaya E. A. Primeneniye infrakrasnoy spektroskopii v neftyanoy geokhimii [Application of infrared spectroscopy in petroleum geochemistry]. Leningrad, Nedra Publ., 1971. 140 p. 
8. Garmarudi A. B., Khanmohammadi M., Fard H. G., Guardia M. Origin based classification of crude oils by infrared spectrometry and chemometrics. Fuel, 2019, vol. 236, pp. 1093-1099.

9. Guiliano M., Millef Kister J., Muller J. F. Etude des specters IRTF de charbons francais demineralises et de leurs maceraux. Chim. Physique, 1988, vol. 85, pp. 963-970.

10. Artem'yev V. Yu., Grigor'yev E. V., Shigidin O. A. Infrared spectrometry as one of the control methods in the development of the Achimov deposits of the Urengoy NGCM. Vestnik gazovoy nauki [Bulletin of Gas Science], 2013, no. 1, pp. 21-26 (In Russian).

11. Ivanova L. V., Safieva R. Z., Koshelev V. N. IR spectrometry in the analysis of oil and petroleum products. Vestnik Bashkirskogo universiteta [Bulletin of the Bashkir University], 2008, vol. 13, no. 4, pp. 869-738 (In Russian).

\section{Информация об авторах}

Грушова Евгения Ивановна - доктор технических наук, профессор кафедры нефтегазопереработки и нефтехимии. Белорусский государственный технологический университет (220006, г. Минск, ул. Свердлова, 13a, Республика Беларусь). E-mail: grushova.e@mail.ru

Жолнеркевич Вероника Игоревна - выпускник. Белорусский государственный технологический университет (220006, г. Минск, ул. Свердлова, 13a, Республика Беларусь). E-mail: zholnerkevichv@mail.ru

\section{Information about the authors}

Grushova Evgeniya Ivanovna - DSc (Engineering), Professor, the Department of Oil and Gas Processing and Petroleum Chemistry. Belarusian State Technological University (13a, Sverdlova str., 220006, Minsk, Republic of Belarus). E-mail: grushova.e@mail.ru

Zholnerkevich Veronika Igorevna - graduate. Belarusian State Technological University (13a, Sverdlova str., 220006, Minsk, Republic of Belarus).E-mail: zholnerkevichv@mail.ru 